\title{
COMPARATIVE EVALUATION OF LOW-LEVEL LASER THERAPY (LLLT) VERSUS SODIUM HYALURONATE WITH ARTHROCENTESIS IN MANAGEMENT OF TEMPOROMANDIBULAR JOINT DISORDERS (TMD): A CLINICAL RANDOMIZED CONTROLLED STUDY
}

\author{
Bakry Saleh Ahmed", Awad Sherif** and Kamel Heba M.*
}

\begin{abstract}
Purpose: Temporomandibular joint disorders are one of the most common cause of pain of non-dental origin in the orofacial region and is characterized by pain, joint sounds, and restricted mandibular movements. This disorder is known to be multifactorial. There are wide varieties of treatment for the TMD, including non-surgical and surgical treatments. Recently, the low-level laser therapy (LLLT) has been used as a treatment modality to the TMDs.
\end{abstract}

Aim: The aim of this study was to compare and evaluate the effect of low-level laser therapy (LLLT) versus sodium hyaluronate with arthrocentesis in management symptoms of temporomandibular joint disorders (TMD).

Patients and Methods: This was a clinical randomized controlled study conducted on 40 patients with a total of 40 joints ( 3 males and 37 females) diagnosed with TMDs. The patients were randomly divided into 2 groups. Group A (Laser group) received active application of the low-level laser therapy (LLLT). Group B (Arthrocentesis group) received combined arthrocentesis and low molecular weight sodium hyaluronate intracapsular injection.

Results: When comparing the two groups, there were no statistically significant differences; between group A and group B regards changes in measuring pain on visual analogue scale (VAS) and maximum painless opening from pre-operative till post-operative at one month. While, there were statistically significant differences; between the two from pre-operative till post-operative at three months follow up periods.

Conclusion: We can conclude from this study that the use of laser is successful when it is applied in a proper way, although the exact mechanism is not yet well understood. Establishment of a specific protocol is still lacking in the literature, also the studies comparing between the two treatment modalities presented in the following research. So, we recommend performing studies with large number of patients and longer time of follow up.

KEYWORDS: TMJ, LLLT, sodium hyaluronate, arthrocentesis.

\footnotetext{
* Associate Professor, Oral Surgery Department, Faculty of Dentistry, Cairo University, Egypt

** Assistant Researcher in Surgery and Oral Medicine in National Research Center
} 


\section{INTRODUCTION}

The American Academy of Orofacial pain defines temporomandibular disorders (TMDs) as "a collective term that has variety of clinical problems that involve the masticatory muscles, the mandibular joint (TMJ) and the associated structures" (1).

Temporomandibular disorders (TMDs) is one of the most common cause of pain of non-dental origin in the orofacial region and is characterized by pain, joint sounds, and restricted mandibular movements (2). The etiological factors of TMD are known to be multifactorial, including the parafunctional habits, physiological and occlusal factors. ${ }^{(3)}$

Symptoms of TMD include headaches, tenderness of the masticatory muscles, and clicking or locking of the TMJ. ${ }^{(4)}$ Among the several symptoms of TMD, it has been found that the chief complain of the patient with TMD is the masticatory muscle pain. This is usually associated with tension and fatigue, ranging from mild sensitivity to extreme discomfort, and is frequently worsened by function of the muscles involved. ${ }^{(5,6)}$

There are wide varieties of treatment for the TMD, including non-surgical and surgical treatments ${ }^{(7)}$. The non-surgical treatment consists of pharmacological, occlusal and physical therapy. Pharmacological therapy includes non-steroidal anti-inflammatory drugs (NSAIDs), antidepressants, muscle relaxants, while occlusal and physical therapy includes moist heat, ultrasound, laser, exercises, transcutaneous electrical nerve stimulation (TENS), microwave, and manual therapy. ${ }^{(8,9)}$

Physical therapy is used in the treatment of TMD due to its ability to reduce pain, and decrease inflammation. This leads to the restoration of the normal joint function which helps the patient to return to his normal daily activity ${ }^{(\mathbf{1 0})}$.

Low-level laser therapy (LLLT) has recently been used to decrease pain intensity and improve maximal mouth opening (MMO) in both acute and chronic TMD patients. ${ }^{(11)}$ LLLT has the advantages of easy application, limited treatment period and minimum contraindications, due to its analgesic, anti-inflammatory and regenerative effects. ${ }^{(\mathbf{8}, 9)}$

Low-level laser therapy (LLLT) acts via photobiology or bio-stimulation, changing cell and tissue functions. It acts on the cell, leading to the production of more adenosine triphosphate (ATP) and decreasing the need of the cell for oxygen. LLLT increases serotonin and endorphin levels and reduces prostaglandin (PGE 2) and interleukin (IL-1) beta levels, thereby reducing pain. The inflammation is reduced by inhibiting plasminogen activator, which is responsible for collagen breakdown, and increasing collagen deposition. ${ }^{(1)}$

Another well-known treatment modality for the TMD is Arthrocentesis. Arthrocentesis could be performed independently or followed by injection of intracapsular joint medication. ${ }^{(13,14)}$ Many drugs were injected intra-articularly in the treatment of TMD as corticosteroids, sodium hyaluronate, bupivacaine, lidocaine and morphine. ${ }^{(15)}$

Alpaslan (16) reported that arthrocentesis with injection of sodium hyaluronate appeared to be superior to arthrocentesis alone, especially in patients with closed lock TMJ. This was attributed to the faster and longer effect of the sodium hyaluronate on pain relief. ${ }^{(16)}$

Hyaluronic acid is a normal product secreted from the joint tissues which serves as a lubricant, anti-inflammatory, and pain-reliever. Evidence based findings of reduced HA molecular weight and its concentrations in arthritic joints inspired the development of injectable preparations of HA to restore the properties of synovial fluid, so-called visco-supplementation. ${ }^{(17)}$

In TMDs, intra-articular HA is used in two different treatment strategies. It is administered alone for visco-supplementation or as an adjunct to arthrocentesis. ${ }^{(18)}$ Several studies reported that the use of HA after arthrocentesis resulted in more improvement of treatment outcome including decrease 
in pain and increase in jaw movements especially in patients with closed lock. They attributed this to the long-term lubricating and anti-inflammatory effect of HA. ${ }^{(19,20)}$

The aim of this study was to compare and evaluate the effect of low-level laser therapy (LLLT) versus sodium hyaluronate with arthrocentesis in management symptoms of temporomandibular joint disorders (TMD).

\section{PATIENTS AND METHODS}

\section{Study Design}

This was a clinical randomized controlled study conducted on 40 patients with a total of 40 joints ( 3 males and 37 females) diagnosed with temporomandibular joint disorders. The patients were randomly divided into 2 groups, each group consists of 20 patients. Group A (Laser group) received active application of low-level laser therapy (LLLT) using LASOTRONIX (ul. Ztynia 1, 05-500 Piaseczno, Poland). Each joint received 10 single daily doses for 10 days or every second day. Group B (Arthrocentesis group) received combined arthrocentesis and low molecular weight sodium hyaluronate (Hyalgan $\left.{ }^{\circledR}\right)$ intracapsular injection. The study was conducted in the Faculty of Dentistry, Cairo University, department of oral and maxillofacial surgery. A detailed informed written consent including the details of surgery and the possible complications was obtained from all patients.

\section{Eligibility Criteria}

\section{The patients included in the study fulfilled the fol- lowing criteria:}

Inclusion criteria are: patients with TMJ pain of score at least 5 on a $0-10$ visual analog scale (VAS) on jaw function or rest (where the endpoints were 0 $=$ no pain and $10=$ worst pain), patients with sounds during mandibular movements (clicking, pooping), patient with functional disability and finally, patient with age range 18-45 years with no sex predilection.
Exclusion criteria are: Patients with previous temporo-mandibular surgeries, patients diagnosed with systemic muscular or joint disease (e.g., fibromyalgia, muscular disorders, rheumatoid arthritis, and anchored disc phenomenon), patients with dental causes for the pain, patients who sustained previous facial fracture (post traumatic condyle syndrome), patients on previous treatment of TMJ pain (e.g.: occlusal splints), and finally, patients with tumors and lesions of the TMJ.

\section{Randomization}

This study was a randomized clinical controlled trial. Patients were randomly assigned into two equal groups: group (A) and group (B) according to the website (http//www.random.org.eg). Each group consisted of 20 patients.

\section{Preoperative evaluation:}

Preoperative evaluation of the patients included detailed history of: pain, joint dysfunction, previous joint treatment, presence of associated symptoms and past medical and dental history; and clinical examination for the temporo-mandibular regions and masticatory muscles. Data for each patient were collected in his or her own questionnaire and examination chart.

Moreover, measuring the maximum painless mouth opening and pain on visual analogue scale (VAS) were performed. Also, TMJ was examined by palpation to determine the presence of TMJ tenderness or pain, the translatory movement of the condyle during different mandibular movements and finally the presence or absence of joint sound.

\section{Methodology}

\section{Laser application (Group A)}

Asking the patient to open widely in order to locate the anatomic landmarks to permit drawing of the articular fossa and then to close lightly on the posterior teeth to draw the condyle within the glenoid fossa. 
The LLLT application was achieved through Smart M lasotronix Pro diode laser (Figure 1), the wavelength used was of $635 \mathrm{~nm}$, and with frequency of CW Hz. The laser radiation was applied directly in the joint at the height of the joint capsule with mouth in closed and opened position. The dose was 10 doses per joint. The total cycle dose was 100 , and the cycle was repeated for 10 days or every second day. The tip of the applicator was used in a slow circular movement to allow for complete exposure of the target area to the laser beam (Figure 2).

Smart M Pro laser device can be used for a variety of purposes, including cutting, coagulation and tissue vaporization. It can be used also for therapeutic purposes as well as biostimulation due to the high-end optical system and the availability of different light sources as well as flexible fiber optic with a variety of handpieces (Figure 3).

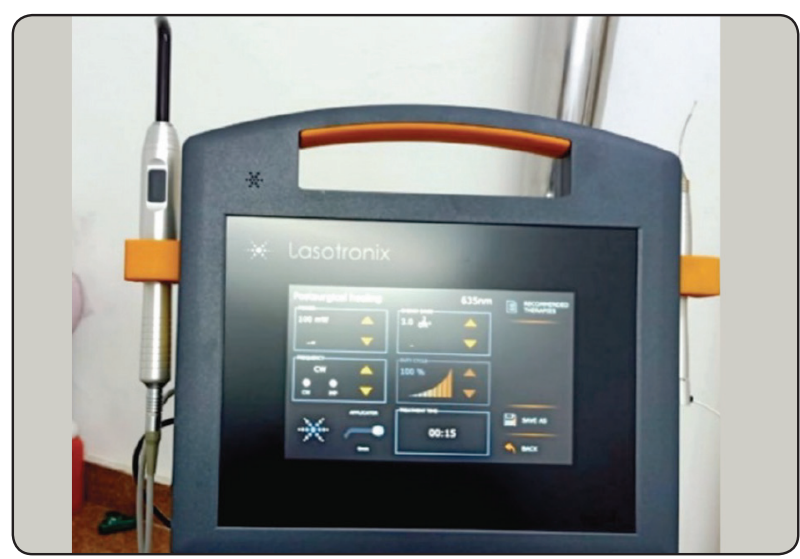

Fig. (1) SMART M Pro laser device.

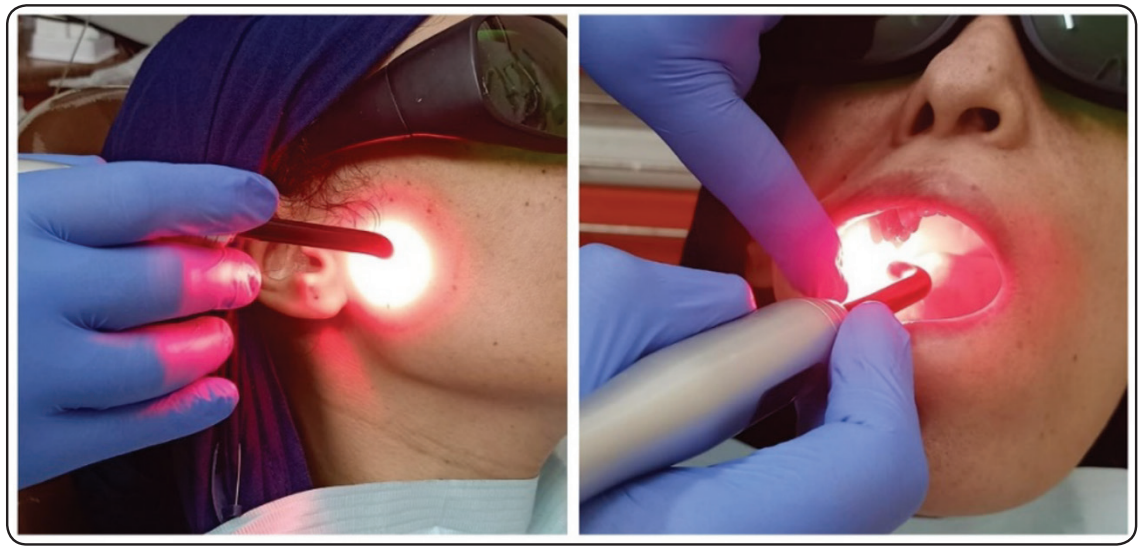

Fig. (2)Application of the laser treatment on the affected TMJ in closed and open position.

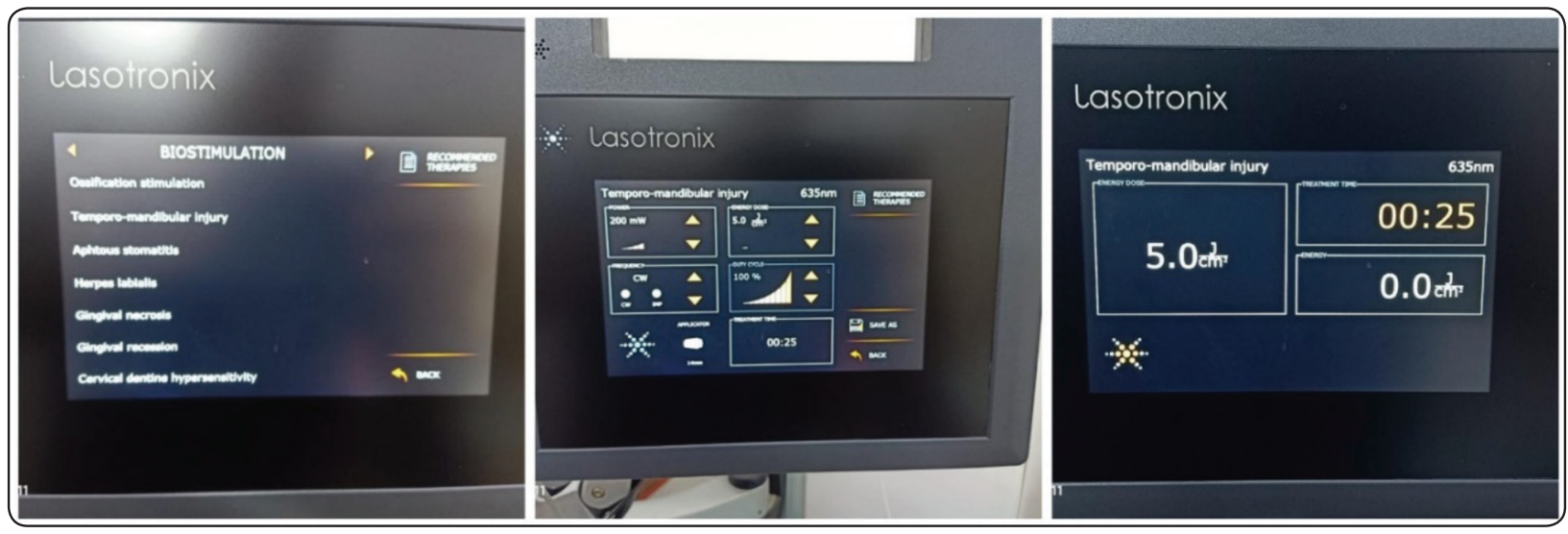

Fig. (3) SMART M Pro laser device in use for treatment of TMJ disorder. 


\section{Group B (Arthrocentesis group):}

Arthrocentesis procedures of the superior joint compartment were performed by local anesthesia by giving intra articular anesthesia or by auricular nerve block. The external auditory canal was protected from fluid and blood accumulation using cotton piece. Skeletal landmarks including the glenoid fossa, articular eminence, and a canthal-tragal line, were marked with a marking pen. A line was drawn from the lateral canthus of the eye till the tip of the tragus of the ear. A point was marked being $10 \mathrm{~mm}$ anterior to the tragus along the canthal-tragal line and $2 \mathrm{~mm}$ inferior to the line. This point represented the puncture site of the first needle (21-guge needle) which introduced us to the posterior recess of the upper joint space. The skin was penetrated at the first point by the needle followed by the injection of $3 \mathrm{~mL}$ lactated Ringer's solution to distend and insufflate the joint space.

The second entry point was located at the same level and posterior to the first point by $3 \mathrm{~mm}$. This second point represented the site of the entry of the outflow needle also in the posterior recess. After placement of out flow needle, joint lavage was performed using continuous irrigation of $200 \mathrm{ml}$ Ringer's lactate (Ringer's lactate, Nile co. Egypt) solution with $5 \mathrm{cc}$ plastic syringe. After termination of the lavage procedure gentle manipulation of the mandible was done in opening, protrusion and lateral excursion in order to release adhesions and reestablish the normal range of motion. After termination of the lavage procedures the out-flow needle was removed and the inflow needle was used to inject a commercially available hyaluronic acid (Hyalgan ${ }^{\circledR}$ Nordisk co., Egypt, Prefilled syringe with $2 \mathrm{ml}$ of water containing $20 \mathrm{mg}$ of hyaluronic acid sodium salt). After injection, the inflow needle was removed and penetration sites were cleaned and pressured to decrease edema and then were covered by Steris trips (Figure 4).

\section{Post-operative medications:}

1. Anti-inflammatory and analgesic (Ibuprofen $600 \mathrm{mg}$ capsules two times per day for a week) (Brufen, Abbott co., Egypt).

2. Antibiotic (amoxicillin \& clavulanic acid $1 \mathrm{gm}$ two times per day for a week) (Augmentin, GSK co., Egypt).

3. Muscle relaxant (Orphenadrine citrate, aspirin and caffeine Multilayer tablets one time per day for two weeks) (Norgesic, Epico co., Egypt).

4. Antiedematous (chemotrypsin 300 IU, Tryp$\sin 300 \mathrm{IU}$, one coated tablet three times per day for a week) (Alphintern, Amoun co., Egypt).

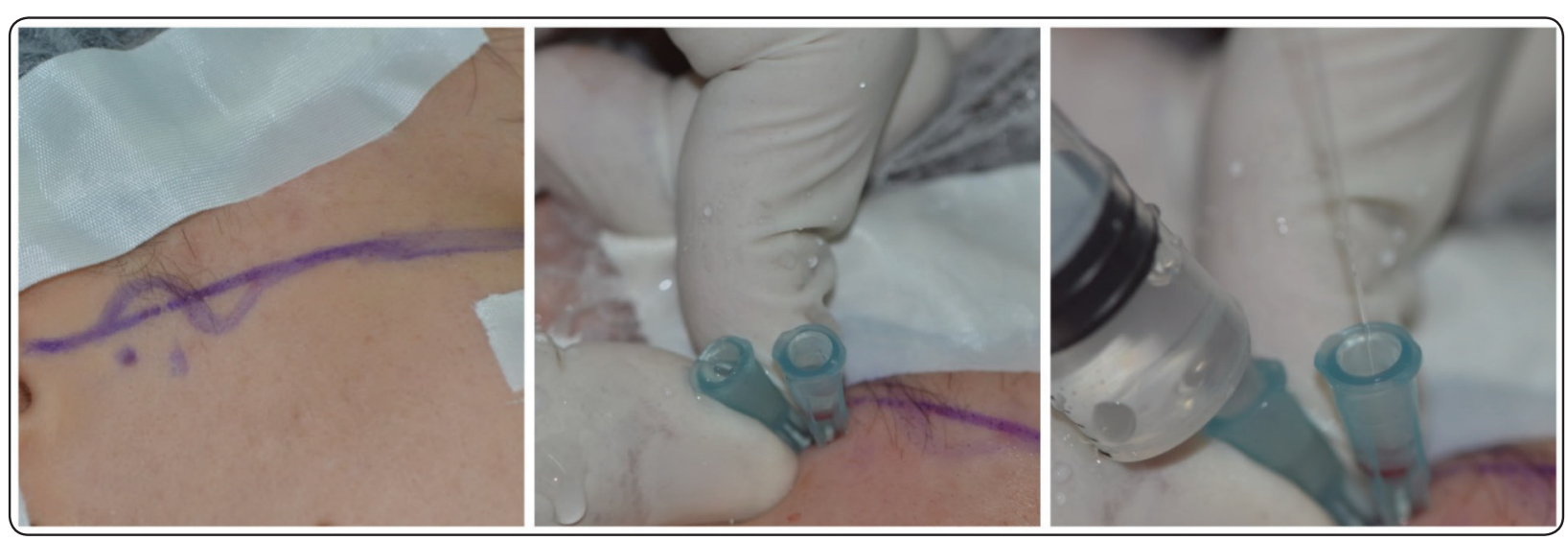

Fig. (4) Entry points for arthrocentesis and inflow and outflow needles in place 


\section{Diet instructions and physical therapy:}

1. Soft diet for 2 weeks.

2. Gradual opening exercise starting from day 3 postoperative, beginning by opening the mouth 2 $\mathrm{cm}$ and gradually increasing $0.5 \mathrm{~cm}$ per day until reaching at least 3.5 inter-incisal distance after 1 week and maintaining exercise for 1 month.

All cases were submitted for follow up visits to evaluate the patients at baseline and 1 and 3 months after intervention.

\section{The following parameters were Assessed:}

1. VisualAnalogue Scale (VAS) for pain intensity: obtained by asking the patient to define the degree of pain on a scale from 0 to 10 where the endpoints were $0=$ no pain and $10=$ worst pain.

2. Maximum Painless opening: obtained by measuring the distance between the upper centrals and the lower centrals in millimeters after the patient opened his mouth comfortably as wide as he/she can without feeling pain.

\section{Risk Minimization:}

1. Failure of the procedure to improve the patient mouth opening and relief pain was compensated by further surgical intervention.

2. A very rare complication with very small percentage was temporary paresis of temporal branch of the facial nerve. This can be avoided by proper surgical technique $\&$ if occurred, the patient was given vitamin B injection \& it is reversible within 2 months.

\section{Data Management and Analysis:}

The collected data was revised, coded, tabulated and introduced to a PC using Statistical package for Social Science (SPSS 24 for windows; SPSS Inc, Chicago, IL). Data was presented and suitable analysis was done according to the type of data obtained for each parameter.

\section{I. Descriptive statistics:}

- Mean.

- Standard deviation ( $\pm \mathrm{SD})$

- Minimum and maximum values (range) for numerical data.

\section{II. Analytical statistics:}

- Paired-Samples T Test was used to assess the statistical significance of the difference between two means of one quantitative variable measured twice for the same study group.

- The Independent-Samples T Test was used to assess the statistical significance of the difference between two study group means.

\section{P-value: level of significance:}

- P> 0.05: Non-significant (NS).

- $\mathrm{P} \leq 0.05$ : Significant (S).

- $\mathrm{P} \leq 0.01$ : Highly significant (HS).

\section{RESULTS}

The study was conducted on 40 patients with a total of 40 joints ( 3 males and 37 females) diagnosed with temporomandibular joint disorders. The present study was done to compare and evaluate the effect of low-level laser therapy (LLLT) versus sodium hyaluronate with arthrocentesis in management of the symptoms of temporomandibular joint disorders (TMD). The age ranged from 18 to 42 years. About $27.5 \%$ suffered from pain \& limitation; $10 \%$ suffered from pain \& clicking sound and $12.5 \%$ suffered from severe pain. (Table 1)

TABLE (1) Demographic features of patients

\begin{tabular}{|c|c|c|}
\hline & & Percent \\
\hline \multirow{2}{*}{ Gender } & Males & $7.5 \%$ \\
\cline { 2 - 3 } & Females & $92.5 \%$ \\
\hline \multirow{3}{*}{$\begin{array}{c}\text { Signs and } \\
\text { Symptoms }\end{array}$} & Pain \& limitation & $27.5 \%$ \\
\cline { 2 - 3 } & Pain \& clicking sound & $10 \%$ \\
\cline { 2 - 3 } & Severe pain & $12.5 \%$ \\
\hline
\end{tabular}




\section{Evaluation of Group A (Laser group):}

This group contained 20 patients with a total of 20 joints. All patients were treated with LLLT application through Smart M lasotronix Pro diode laser. The laser radiation was applied directly in the joint at the height of the joint capsule with mouth in closed and opened position.

All the patients were followed up at 1 and 3 -months intervals with no drop outs. Tables $(2,3)$, show the mean value of VAS and maximum painless mouth opening of these patients preoperatively, 1 month, 3 months postoperatively.

\section{VAS of pain}

The mean pain intensity, as measured by VAS, gradually decreased by time. Preoperatively, the mean pain intensity was 8.20 and it decreased significantly to 3.50 at 1 month follow up ( $\mathrm{P}$ value $<0.0001)$ and it became 1.55 at 3 months follow up ( $\mathrm{P}$ value $<0.0001)$ (Table 2). All patients showed gradual decrease of pain by time.

TABLE (2) Comparison between pre and post Laser application regards VAS among group (A):

\begin{tabular}{|c|c|c|c|c|c|c|c|}
\hline \multicolumn{2}{|c|}{ Group I (LL) } & $\mathbf{N}$ & Mean & SD & $\mathbf{T}$ & P value & Sig. \\
\hline \multirow{4}{*}{ VAS } & Pre & 20 & 8.20 & 1.24 & \multirow[b]{2}{*}{20.39} & \multirow[b]{2}{*}{$<0.0001$} & \multirow[b]{2}{*}{ HS } \\
\hline & $\begin{array}{l}\text { Post- one } \\
\text { month }\end{array}$ & 20 & 3.50 & 0.95 & & & \\
\hline & Pre & 20 & 8.20 & 1.24 & \multirow[b]{2}{*}{22.72} & \multirow[b]{2}{*}{$<0.0001$} & \multirow[b]{2}{*}{ HS } \\
\hline & $\begin{array}{l}\text { Post- } \\
\text { Three } \\
\text { months }\end{array}$ & 20 & 1.55 & 0.69 & & & \\
\hline
\end{tabular}

\section{Paired-Samples T Test}

The mean of VAS for post Laser application at one month and three months was lower than that for pre-surgery. That difference was statistically highly significant.

\section{Maximum painless opening}

The mean maximum painless mouth opening in these patients improved from $24.10 \mathrm{~mm}$ to $31.90 \mathrm{~mm}$ and $36.49 \mathrm{~mm}$ at 1 and 3 months follow up respectively (P value $<0.0001$ and 0.0001 respectively). (Table 3). All patients showed gradual increase in maximum painless opening reaching their peak at 3 months follow up.

TABLE (3) Comparison between pre and post Laser application regards maximum painless opening among group $\mathrm{A}$

\begin{tabular}{|c|c|c|c|c|c|c|c|}
\hline \multicolumn{2}{|c|}{ Group I (LL) } & $\mathbf{N}$ & Mean & SD & $T$ & $P$ value & Sig. \\
\hline \multirow{4}{*}{ 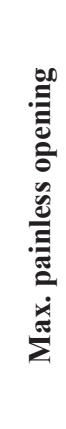 } & Pre & 20 & 24.10 & 3.40 & \multirow[b]{2}{*}{-14.82} & \multirow[b]{2}{*}{$<0.0001$} & \multirow[b]{2}{*}{ HS } \\
\hline & $\begin{array}{l}\text { Post- one } \\
\text { month }\end{array}$ & 20 & 31.90 & 3.55 & & & \\
\hline & Pre & 20 & 24.10 & 3.40 & \multirow[b]{2}{*}{-23.54} & \multirow[b]{2}{*}{$<0.0001$} & \multirow[b]{2}{*}{ HS } \\
\hline & $\begin{array}{l}\text { Post- } \\
\text { Three } \\
\text { months }\end{array}$ & 20 & 36.45 & 2.24 & & & \\
\hline
\end{tabular}

\section{Paired-Samples T Test}

The mean of maximum painless opening for post Laser application; at one month and three months was higher than that for pre-surgery. That difference was statistically highly significant.

\section{Evaluation of Group B (Arthrocentesis group):}

This group contained 20 patients with a total of 20 joints. All patients were treated with arthrocentesis along with sodium hyaluronate intracapsular injection and were all followed up at 1 and 3-months intervals with no drop outs. Tables (6-9), show the mean value of VAS, maximum painless mouth opening, maximum unassisted opening and maximum assisted opening, 1 month, 3 months postoperatively. 


\section{VAS of pain}

The mean pain intensity, as measured by VAS, gradually decreased by time. Preoperatively, the mean pain intensity was 9.15 and it decreased significantly to 3.95 at 1 month follow up (P value $<0.0001$ ) and it became 1.70 at 3 months follow up ( $\mathrm{P}$ value < 0.0001) (Table 4). All patients showed gradual decrease of pain by time.

TABLE (4) Comparison between pre and post (ARSIS+HA) regards VAS among group B

\begin{tabular}{|c|c|c|c|c|c|c|c|}
\hline \multicolumn{2}{|c|}{$\begin{array}{l}\text { Group II } \\
\text { (ARSIS + HA) }\end{array}$} & $\mathbf{N}$ & Mean & SD & $\mathbf{T}$ & $P$ value & Sig. \\
\hline \multirow{4}{*}{ VAS } & Pre & 20 & 9.15 & 1.09 & \multirow[b]{2}{*}{30.29} & \multirow[b]{2}{*}{$<0.0001$} & \multirow[b]{2}{*}{ HS } \\
\hline & $\begin{array}{l}\text { Post- one } \\
\text { month }\end{array}$ & 20 & 3.95 & 0.94 & & & \\
\hline & Pre & 20 & 9.15 & 1.09 & \multirow[b]{2}{*}{31.73} & \multirow[b]{2}{*}{$<0.0001$} & \multirow[b]{2}{*}{ HS } \\
\hline & $\begin{array}{l}\text { Post- } \\
\text { Three } \\
\text { months }\end{array}$ & 20 & 1.70 & 0.57 & & & \\
\hline
\end{tabular}

\section{Paired-Samples T Test}

The mean of VAS for post (ARSIS +HA) at one month and three months, was lower than that for pre-surgery. That difference was statistically highly significant.

\section{Maximum painless opening}

The physical function in these patients where the mean maximum painless mouth opening improved from $24.85 \mathrm{~mm}$ to $31.75 \mathrm{~mm}$ and $35.20 \mathrm{~mm}$ at 1 and 3 months follow up respectively ( $\mathrm{P}$ value $<0.0001$ and 0.0001 respectively). (Table 5). All patients showed gradual increase in maximum painless opening reaching their peak at 3 months follow up.
TABLE (5) Comparison between pre and post (ARSIS +HA) regards maximum painless opening among group $\mathrm{B}$

\begin{tabular}{|c|c|c|c|c|c|c|c|}
\hline \multicolumn{2}{|c|}{$\begin{array}{l}\text { Group II } \\
\text { (ARSIS +HA) }\end{array}$} & $\mathbf{N}$ & Mean & SD & $\mathbf{T}$ & $P$ value & Sig. \\
\hline \multirow{4}{*}{ 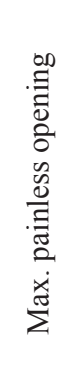 } & Pre & 20 & 24.85 & 4.34 & \multirow[b]{2}{*}{-13.08} & \multirow[b]{2}{*}{$<0.0001$} & \multirow[b]{2}{*}{ HS } \\
\hline & $\begin{array}{l}\text { Post- one } \\
\text { month }\end{array}$ & 20 & 31.75 & 5.06 & & & \\
\hline & Pre & 20 & 24.85 & 4.34 & \multirow[b]{2}{*}{-14.62} & \multirow[b]{2}{*}{$<0.0001$} & \multirow[b]{2}{*}{ HS } \\
\hline & $\begin{array}{l}\text { Post- Three } \\
\text { months }\end{array}$ & 20 & 35.20 & 5.06 & & & \\
\hline
\end{tabular}

\section{Paired-Samples T Test}

The mean of maximum painless opening for post (ARSIS+HA) at one month and three months was higher than that for pre-surgery. That difference was statistically highly significant.

\section{Comparison between the Group A \& Group B:}

Comparing group, A to group B yielded some statistically significant difference regarding the 2 efficacy parameters used in our study. There were no statistically significant differences; between group A and group B regards changes in VAS from preoperative till post-operative at one month. While, there were statistically significant differences; between group A and group B regards changes in VAS from pre-operative till post-operative at three months follow up periods $(\mathrm{P}$ value $=0.090 \& 0.040$ respectively) (Table 6). Moreover, there were no statistically significant differences; between group A and group $\mathrm{B}$ regards changes in maximum painless opening from pre-operative till post-operative at one month. While, there were statistically significant differences; between 2 groups at three months follow up visit $(\mathrm{P}$ value $=0.235 \& 0.029$ respectively) (Table 7). 
TABLE (6) Comparison between the two groups regards changes in VAS

\begin{tabular}{|c|c|c|c|c|c|c|c|}
\hline \multicolumn{2}{|l|}{ VAS } & $\mathbf{N}$ & Mean & SD & t & P value & Sig. \\
\hline \multirow{2}{*}{$\begin{array}{l}\text { Pre till } 1 \\
\text { month }\end{array}$} & Group A & 20 & -4.70 & 1.03 & \multirow{2}{*}{1.74} & \multirow{2}{*}{0.090} & \multirow{2}{*}{ NS } \\
\hline & Group B & 20 & -5.20 & 0.77 & & & \\
\hline \multirow{2}{*}{$\begin{array}{l}\text { Pre till } 3 \\
\text { months }\end{array}$} & Group A & 20 & -6.65 & 1.31 & \multirow{2}{*}{2.13} & \multirow{2}{*}{0.040} & \multirow{2}{*}{$\mathrm{S}$} \\
\hline & Group B & 20 & -7.45 & 1.05 & & & \\
\hline
\end{tabular}

\section{The Independent-Samples T Test}

There were no statistically significant differences; between group A and group B regards changes in VAS from pre-operative till post-operative at one month. While, there were statistically significant differences; between group A and group B regards changes in VAS from pre-operative till postoperative at three months.

TABLE (7) Comparison between the two groups regards changes in maximum painless opening

\begin{tabular}{|c|c|c|c|c|c|c|c|}
\hline \multicolumn{2}{|c|}{$\begin{array}{l}\text { Max. Painless } \\
\text { Opening }\end{array}$} & $\mathbf{N}$ & Mean & SD & $\mathbf{t}$ & Pvalue & Sig. \\
\hline \multirow{2}{*}{$\begin{array}{c}\text { Pre till } 1 \\
\text { month }\end{array}$} & Group A & 20 & 7.80 & 2.35 & \multirow{2}{*}{1.21} & \multirow{2}{*}{0.235} & \multirow{2}{*}{ NS } \\
\hline & Group B & 20 & 6.90 & 2.36 & & & \\
\hline \multirow{2}{*}{$\begin{array}{l}\text { Pre till } 3 \\
\text { months }\end{array}$} & Group A & 20 & 12.35 & 2.35 & \multirow{2}{*}{1.27} & \multirow{2}{*}{0.029} & \multirow{2}{*}{ S } \\
\hline & Group B & 20 & 10.35 & 3.17 & & & \\
\hline
\end{tabular}

\section{The Independent-Samples T Test}

There were no statistically significant differences; between group A and group B regards changes in max. painless opening from pre-operative till post-operative at one month. While, there were statistically significant differences; between group A and group B regards changes in maximum painless opening from pre-operative till post-operative at three months.

\section{DISCUSSION}

Temporomandibular disorders are found in a great portion of the population. This pathologic condition is often characterized by pain that can be severe to the extent of limiting the mandibular movements and affecting the patient's quality of life $\mathrm{e}^{(21,22)}$.

The aim of the current study was to compare the effect of low-level laser therapy and arthrocentesis using sodium hyaluronate in improving the symptoms of temporomandibular joint disorders.

The results of our study showed that the intensity of pain measured via VAS decreased gradually by time in each group through the study follow up intervals. When comparing the changes between the two groups, there were statistically significant decrease in pain VAS between group A and group $B$ at three months follow up periods in favor to the laser group, however this difference was not observed in the one month follow up period. That indicates that LLLT showed more pain relief than arthrocentesis using hyaluronate in the late phase of therapy.

Although the analgesic effect mechanism of LLLT is not clear yet, but as explained by several researches, LLLT may decrease pain by many mechanisms: increasing production of endogenous opiates, increasing glucocorticoids excretion by the kidneys, improving the quality of local circulation, decreasing edema by improving the flow of lymphatics, lowering the nerve membrane permeability and acceleration of the wound healing ${ }^{(9,23)}$

This result was in accordance with Khairna $\mathbf{S}$ et al $2019{ }^{(24)}$ who compared between LLLT and ultrasound therapy in reducing TMD pain. They found that there was a statistically significant difference when comparing VAS scores for pain before and after treatment for both groups separately. However, when comparing the post therapeutic pain VAS scores between the both groups, there was a statistically significant difference favoring the Laser group. 
However, in a study made by Rezazadeh $\mathbf{F}$ et al $2017{ }^{(25)}$, comparing the effects of Transcutaneous Electrical Nerve Stimulation (TENS), and LLLT on drug-resistant TMD, they reported significant reduction in the pain VAS score in both groups. But there was no significant difference between the two treatment modalities during the treatment; however, TENS was more effective in pain reduction in follow-ups.

Mazzetto MO et al $2010{ }^{(26)}$ found also that the use of LLLT has decreased the intensity of the painful symptoms but in the immediate treatment phase.

The results of the current study showed that the mean of maximum painless opening at one month and three months was higher than that for pre-surgery in both groups. That difference was statistically highly significant. Moreover, there were no statistically significant differences; between both groups regarding changes in maximum painless opening from pre-operative till post-operative at one month. While, there were statistically significant differences; between the two groups at three months follow up visit.

The improvements in mandibular movements in the arthrocentesis group could be contributed to the simplicity and minimally invasive lavage and lysis of the TMJ under hydraulic pressure. This pressure helps in eliminating the vacuum effect and releasing the adhesions in the same time, permitting a free movement of the articular disc during function and restoring the normal range of motion. Also, the washing out of pain and inflammatory mediators helps in decreasing pain and improving symptoms. With the additional use of HA as an intra-joint medication, the whole procedure outcome was improved, duo to its potent anti-inflammatory effect, and functioning in joint lubrication. ${ }^{(27)}$

As regarding the improvement happened with the LLLT, still there are controversies among the literature. (21) LLLT is considered a noninvasive, fast and safe intervention, and also drug-free, which might be of great help to patients with TMDs ${ }^{(28)}$. The response to treatment by LLLT depends on several factors such as: the type of laser, the dose, frequency and the type of the target tissue. Due to the multifactorial factors that control the success of LLLT treatment, unsatisfactory outcome can happen due to very high or low dose, inadequate number of sessions, insufficient energy density, and wrong diagnosis of the case ${ }^{(26)}$.

Although this wide controversy among the published literature, our results come in accordance with who have found also improvement in the mandibular movements (MIO). ${ }^{(7,28)}$

So, it is obvious that the use of laser is successful when it is applied in a proper way, although the exact mechanism is not yet well understood. ${ }^{(29)}$ Establishment of a specific protocol is still lacking in the literature, also the studies comparing between the two treatment modalities presented in the following research. So, we recommend performing studies with large number of patients and longer time of follow up.

\section{REFERENCES}

1. Scrivani SJ, Keith DA, Kaban LB. Temporomandibular disorders. N Engl J Med 2008; 359: 2693-705.

2. Magnusson T, Egemark I, Carlsson GE. A longitudinal epidemiologic study of signs and symptoms of temporomandibular disorders from 15 to 35 years of age. J Orofac Pain. 2000; 14:310-9.

3. Kato MT, Kogawa EM, Santos CN, Conti PC. TENS and low-level laser therapy in the management of temporomandibular disorders. J Appl Oral Sci. 2006; 14:130-135.

4. Dworkin, S.F., and LeResche, L. Research diagnostic criteria for temporomandibular disorders: Review, criteria, examinations and specifications, criteria. J. Craniomandib. Disord. 1992; 6:301-355.

5. De Kanter RJ, Truin GJ, Burgersdijk RC, Van't Hof MA, Batistuzzi PG, Kalsbeek H, et al. Prevalence in the Dutch adult population and a meta-analysis of signs and symptoms of temporomandibular disorder. J Dent Res. 1993; 72:1509-18.

6. Gesch D, Bernhardt O, Alte D, Schwahn C, Kocher T, John U, et al. Prevalence of signs and symptoms of temporomandibular disorders in an urban and rural German population: results of a population-based study of health in Pomerania. Quintessence Int. 2004; 35:143-50. 
7. Shukla D, Muthusekhar MR. Efficacy of low-level laser therapy in temporomandibular disorders: A systematic review. Natl J Maxillofac Surg 2016; 7: 62-6.

8. Venancio Rde A, Camparis CM, Lizarelli Rde F. Low intensity laser therapy in the treatment of temporoman-dibular disorders: a double-blind study. J Oral Rehabil. 2005; 32: 800-807.

9. Carvalho CM, de Lacerda JA, dos Santos Neto FP, Cangussu MC, Marques AM, Pinheiro AL. Wave-length effect in temporomandibular joint pain: a clinical experience. Lasers Med Sci. 2010; 25: 229-232.

10. Draper DO. Facts and misfits in ultrasound therapy: Steps to improve your treatment outcomes. Eur J Phys Rehabil Med 2014; 50: 209-16.

11. Salmos-Brito JA, De Menezes RF, Teixeira CE, Gonzaga RK, Rodrigues BH, et al. Evaluation of low-level laser therapy in patients with acute and chronic temporomandibular disorders. Lasers Med Sci. 2013; 28: 57-64.

12. Emshoff R, Bosch R, Pumpel E, Schoning H, Strobl H. Low-level laser therapy for treatment of temporomandibular joint pain: a double-blind and placebo-controlled trial. Oral Surg Oral Med Oral Pathol Oral Radiol Endod. 2008; 105:452-456.

13. Haddad I: Temporomandibular joint osteoarthrosis: Histopathological study of the effects of intra-articular injection of triamcinolone acetonide. Saudi Medical Journal. 2000; 21 (7): 675.

14. Schindler C, Paessler L, Eckelt U: Severe temporomandibular dysfunction and joint destruction after intra-articular injection of triamcinolone. Journal of Oral Pathology \& Medicine. 2005; 34: 184.

15. Dionne R.A: Pharmacologic treatments for temporomandibular disorders. Oral Surg Oral Med Oral PatholOral Radial Endod. 1997; 83: 134.

16. Alpaslan GH, Alpaslan C. Efficacy of temporomandibular joint arthrocentesis with and without injection of sodium hyaluronate in treatment of internal derangements. J Oral Maxillofac Surg 2001; 59:613-9.

17. Marshall KW: Intra-articular hyaluronan therapy. Current Opinion in Rheumatology. 2000; 5:468.

18. Alpaslan C, Bilgihan A, Alpaslan GH, et al: Effect of arthrocentesis and sodium hyaluronate injection on nitrite, nitrate, and thiobarbituric acid-reactive substance levels in the synovial fluid. Oral Surg Oral Med Oral Pathol Oral RadiolEndod. 2000; 89:686.

19. I.Aktas, S. Yalcin, S.Sencer: Prognostic indicators of the outcome of arthrocentesis with and without sodium hyaluronate injection for the treatment of disc displacement without reduction: a magnetic resonance imaging study. Int. J. Oral Maxillofac. Surg. 2010; 39: 1080-1085.

20. Angel M, Caubet J, Varela L, and Ignacio J: Sodium Hyaluronate Improves Outcomes after Arthroscopic Lysis and Lavage in Patients with Wilkes Stage III and IV Disease J Oral Maxillofac Surg, 2010.

21. Herranz-Aparicio J, Vázquez-Delgado E, Arnabat-Domínguez, España-Tost A, Gay-Escoda C: The use of low-level laser therapy in the treatment of temporomandibular joint disorders. Review of the literature. Med Oral Patol Oral Cir Bucal. 2013 Jul 1;18 (4): e603-12.

22. Haddad Leal de Godoy C, Fernanda da Costa Silva P, Sales de AraujoD, Jansiski Motta LJ,Daniela Aparecida Biasotto-Gonzalez DA et al: Evaluation of effect of lowlevel laser therapy on adolescents with temporomandibular disorder: study protocol for a randomized controlled trial. http://www.trialsjournal.com/content/14/1/229, 2013.

23. Shirani AM, Gutknecht N, Taghizadeh M, Mir M. Lowlevel laser therapy and myofacial pain dysfunction syndrome: a randomized controlled clinical trial. Lasers Med Sci. 2009; 24:715-20.

24. Khairnar S, Bhate K, Kumar S.N., Kshirsagar K, Jagtap B, Kakodkar P: Comparative evaluation of low-level laser therapy andultrasound heat therapy in reducing temporomandibular joint disorder pain. J Dent Anesth Pain Med 2019;19(5):289-294.

25. Rezazadeh F ,Hajian K, Shahidi S, Piroozi S: Comparison of the Effects of Transcutaneous Electrical Nerve Stimulation and Low-Level Laser Therapy on Drug-Resistant Temporomandibular Disorders. J Dent Shiraz Univ Med Sci., 2017 September; 18(3): 187-192.

26. Mazzetto MO, Hotta TH and de Andrade Pizzo RC.Measurements of Jaw Movements and TMJ Pain Intensityin Patients Treated with GaAlAs Laser. Braz Dent J. 2010; 21:356-360.

27. Manfredini D, Bonnini S, Arboretti R: Temporomandibular joint osteoarthritis: an open label trial of 76 patients treated with arthrocentesis plus hyaluronic acid injections. Int. J. Oral Maxillofac. Surg. 38: 827, 2009.

28. Brochado FT, Jesus LH, Carrard VC, Freddo AL, Chaves KD, Martins MD. Comparative effectiveness of photobiomodulation and manual therapy alone or combined in TMD patients: a randomized clinical trial. Braz Oral Res. 2018; 10;32: e50.

29. Mila Leite de Moraes MAIA, Leonardo Rigoldi BONJARDIM et al: Effect of low-level laser therapy on pain levels in patients with temporomandibular disorders: a systematic review. J Appl Oral Sci. 2012;20(6):594-602. 